\title{
Incidence of cancer among bookbinders, printers, photoengravers, and typesetters
}

\author{
V Rafnsson
}

\begin{abstract}
Objectives-To to study the risk of cancer, particularly of lung cancer and bladder cancer, among workers in the printing industry according to different occupations.

Methods-This is a population based retrospective cohort study. The cohort comprised 1332 men and 426 women employed in the printing industry in Iceland according to a published union registry. A computerised file of the cohort was record linked to the Cancer Registry by making use of personal identification numbers. Expected numbers of cases of cancer were calculated on the basis of number of person-years and specific incidences of cancer sites for men and women provided by the Cancer Registry.

Results-Among the men (36 217.5 person-years at risk) there were 125 observed cancers versus 123.66 expected, standardised incidence ratio (SIR) 1.01, $95 \%$ confidence interval $(95 \% \mathrm{CI})$ was 0.84 to 1.20 . The SIR $(95 \% \mathrm{CI})$ for liver cancer was $1.97(0.55$ to 5.20$)$ and the SIR for non-Hodgkin's lymphoma was 2.26 (0.96 to 4.41). No excess risk for cancer was found among women (8631.0 person-years at risk). The SIR (95\% CI) for liver cancer was $4.21(0.47$ to 15.20$)$ and for nonHodgkin's lymphoma it was 4.99 (1.61 to 11.63) among the typesetters. A survey on smoking habits among active and retired union members showed that they smoked less than a random sample of the general population.
\end{abstract}

Conclusion-The cancer site most often reported to show excess risk among printing industry workers has been the lung and the urinary bladder; however, this was not found in the present study. This may be explained by difference in smoking habits among union members compared with the general population. There is a high occurrence of non-Hodgkin's lymphoma, particularly among typesetters, which warrants further studies. (Occup Environ Med 2001;58:523-527)

Department of Preventive Medicine, University of Iceland, Soltun 1, 105 Reykjavik, Iceland V Rafnsson

Correspondence to: Dr V Rafnsson vilraf@hi.is

Accepted 28 March 2001 tional exposure in the printing industry as possibly carcinogenic to humans and the reported studies did show excesses of lung and bladder cancer and the exposures of interest were considered to include many potential carcinogens. ${ }^{1}$ It has been suggested that the inconsistency in cohort studies from the printing industry concerning risk of cancer may be due to the lack of relevant subgrouping for exposures and work tasks. ${ }^{2}{ }^{3}$ A recently published study on women in the printing industry indicating excess of oesophageal, stomach, and ovarian cancersthat is, new cancer sites - supports this need for more detailed surrogates of exposures. ${ }^{4}$ Information on exposure is often the main weakness of register studies and retrospective cohort studies. However, having access to union records from the printing trade made it possible to contribute to the picture by use of the Icelandic Cancer Registry to follow up bookbinders, printers, photoengravers, and typesetters. The aim of the study was to evaluate the risk of cancer in the printing industry according to different occupations, particularly for lung and bladder cancer.

\section{Material and methods}

This is a retrospective cohort study. The cohort comprised all workers born in 1900 or later who were mentioned in a published bookThe Register of the Trade Union of Printers and Bookbinders ${ }^{5}$ - and who were alive in 1955. The register contains all members of several former and present trade unions in Iceland, and is based on the lists of tradesmen kept by the authorities. The register was used to compile a computer file of the members after permission was obtained from the Data Protection Commission, which also permitted a record linkage with other registers. A survey of smoking habits and occupation of the members of the union was made in cooperation with the union and the Safety Committee of the Trade Union of Printers and Bookbinders.

The cohort comprised 1332 men and 426 women. The unions list included the person's name, date of birth, the year they received their licence or the year they started to work in the printing industry and occupation. The name and the date of birth was used to find the identification number in the National Registry, which consists of the date of birth and an additional four digit number. The personal identification numbers were used to link records with the National Registry to discover typographical errors, the date of death, and possible emigration. In this way it was possible to ascertain the vital status for all people. Thus it was possible to define person-years at risk for each subject. The risk period for each person started in 1955 , or the year he or she was licensed or started employment if it was later than 1955. 
The period at risk lasted to the end of 1998 , to the date of death, or date of emigration, whichever came first. The 82 people who had emigrated could not be followed up by the cancer registry after the date of emigration. The individual risk period did not end at the date of cancer diagnosis, theoretically a person could have many cancers, in compliance with the cancer incidences from the cancer registry. In this way person-years were counted within 5 year age categories during the individual calendar years of the study period 1955-98.

The cohort was divided into different occupations according to information from the Register of the Trade Union of Printers and Bookbinders. ${ }^{5}$ Members of the union were manufacturing books, magazines, and newspapers. However, information on what production each worker had been engaged in was not available. According to information from the trade union it was possible to identify three main occupations from the register-namely, bookbinders, printers, and photoengravers and typesetters-and others not fitting into any of the main categories. From the register it was possible to make a more detailed classification into occupation. However, because of small and young groups statistical considerations soon became problematic. This classification was based on first craft obtained or first position held if not a tradesman.

Previously bookbinding was manual work, consisting mainly of sewing, cutting and gluing, but since 1970 it has become mechanised. Hot melted glue was and is still in use. Other glues or limes were either water based or based on organic solvents of different types. There are reports that benzene was used in the bookbinding process in Moscow and Washington until $1958 .{ }^{4}{ }^{6}$ In the present study, however, it is not certain whether the binders were exposed to benzene. The printers have been involved in all types of printing processes during the study period-namely, letterpress, gravure printing, lithography printing, and offset printing. According to measurements in personal samples printers have been exposed to

Table 1 Observed (Obs) and expected (Exp) number of cancers, and SIR (95\% CIs) among 1332 male bookbinders, printers, photoengravers, and typesetters (36217.5 person-years), followed up during 1955-98

\begin{tabular}{lrrrrr}
\hline & & & & \multicolumn{2}{c}{$95 \%$ CI } \\
\cline { 5 - 6 } Cancer sites (ICD-7) & Obs & \multicolumn{1}{c}{ Exp } & SIR & Lower & Higher \\
\hline All cancers (140-205) & & & & & \\
Stomach (151) & 11 & 123.66 & 1.01 & 0.84 & 1.20 \\
Colon (153) & 14 & 8.66 & 0.90 & 0.45 & 1.60 \\
Rectum (154) & 2 & 3.32 & 0.60 & 0.88 & 2.71 \\
Liver (155) & 4 & 1.97 & 2.03 & 0.55 & 5.17 \\
Pancreas (157) & 3 & 3.60 & 0.83 & 0.17 & 2.43 \\
Lung (162) & 15 & 15.78 & 0.95 & 0.53 & 1.57 \\
Prostate (177) & 28 & 24.31 & 1.15 & 0.77 & 1.66 \\
Testis (178) & 4 & 2.21 & 1.81 & 0.49 & 4.63 \\
Kidney (180) & 4 & 6.59 & 0.61 & 0.16 & 1.55 \\
Bladder (181) & 9 & 8.61 & 1.05 & 0.48 & 1.98 \\
Skin melanoma (190) & 1 & 1.97 & 0.51 & 0.01 & 2.83 \\
Other skin (191) & 2 & 3.06 & 0.65 & 0.07 & 2.36 \\
Brain (193) & 4 & 4.55 & 0.88 & 0.24 & 2.25 \\
Thyroid (194) & 1 & 2.81 & 0.36 & 0.00 & 1.98 \\
Non-Hodgkin's lymphoma (200, 202) & 8 & 3.58 & 2.24 & 0.96 & 4.41 \\
Multiple myeloma (203) & 1 & 1.56 & 0.64 & 0.01 & 3.58 \\
Leukaemia (204) & 1 & 3.01 & 0.33 & 0.00 & 1.85 \\
All other sites (145, 150, 160, 161, 161, & & & & & \\
$\quad$ 170, 170, 179, 197, 199, 199, 199, 199) & 13 & 15.80 & 0.82 & 0.44 & 1.41 \\
\hline
\end{tabular}

various organic solvents. ${ }^{7}$ Similarly, the plate making technique has changed over time from manual typesetting to photomechanical methods involving exposure to different chemicals. Typesetters were previously exposed to lead in the form of dust and fumes. In the subgroup of typesetters and photoengravers it was possible to identify those who had started as tradesmen typesetters.

The Cancer Registry in Iceland is a nationwide registry of cases of cancer established in 1955. More than $94 \%$ of cases were verified by histological diagnosis. ${ }^{8}$ Every case was registered by its personal identification number. The computer file of the trade union members was linked to the Cancer Registry by the personal identification numbers. Thus we were able to establish whether the people had cancer or not, and if they had cancer, the cancer site.

The number of expected cancers was calculated on the basis of number of person-years for each 5 year age category and the cancer incidences for the male and female population in Iceland obtained from the Cancer Registry. ${ }^{8}$ The ratio between the observed and expected numbers of cancer-the standardised incidence ratio (SIR) - was calculated with 95\% confidence intervals (95\% CIs) and $\mathrm{p}$ values, assuming a Poisson distribution and making use of Byar's approximation. ${ }^{9}$ A value of $\mathrm{p}<0.05$ was considered to be significant.

A survey on smoking habits and occupation among active and retired union members was performed in the year 2000 with a postal questionnaire, and the participation rate was $55 \%$. These smoking habits were compared with those of the general population as gathered with the same questionnaire used in 1998 by the Committee for Tobacco Use Prevention. ${ }^{10}$ The method Axelson and Steenland have introduced to assess the effect of tobacco smoking ${ }^{11}$ was used to evaluate the possible confounding from smoking on the risk of lung cancer. There seemed to be a consistency in occupation according to the questionnaire and the trade union register, but no systematic evaluations were made because of the low participation rate.

\section{Results}

Table 1 shows the observed and expected number of cases, the SIRs, and 95\% CIs for selected cancer site among all men. Overall cancer incidence was near unity (125 observed versus 123.66 expected, SIR 1.01, 95\% CI 0.84 to 1.20$)$. Significantly increased risks were found for non-Hodgkin's lymphoma (SIR $2.24,95 \%$ CI 0.96 to 4.41 ), although the $95 \%$ CI included unity. A non-significantly increased risk was found for liver cancer. The number according to the seventh revision of the international classification of diseases (ICD-7) of the cancer sites not selected are shown under the category other sites.

Table 2 shows the results for the same cancer sites for male bookbinders. The SIR for all cancer sites was 0.85 and for bladder cancer the SIR was 2.60 , the $95 \%$ CI included unity in both cases. 
Table 3 shows the results among male printers. The SIRs for primary liver cancer was 2.29 based on two cases, other SIRs were near unity. Among the printers a subgroup of 113 offset printers could be identified, and among them

Table 2 Observed (Obs) and expected (Exp) number of cancers, and SIR (95\% CI) among 205 male bookbinders (5654.5 person-years), followed up during 1955-98

\begin{tabular}{|c|c|c|c|c|c|}
\hline \multirow[b]{2}{*}{ Cancer sites (ICD-7) } & \multirow[b]{2}{*}{ Obs } & \multirow[b]{2}{*}{$\operatorname{Exp}$} & \multirow[b]{2}{*}{ SIR } & \multicolumn{2}{|c|}{$95 \% C I$} \\
\hline & & & & Lower & Higher \\
\hline All cancers (140-205) & 23 & 27.10 & 0.85 & 0.54 & 1.27 \\
\hline Stomach (151) & 1 & 2.83 & 0.35 & 0.00 & 1.96 \\
\hline Colon (153) & 2 & 1.95 & 1.03 & 0.12 & 3.70 \\
\hline Rectum (154) & 1 & 0.76 & 1.31 & 0.02 & 7.28 \\
\hline Liver (155) & 0 & 0.76 & 0.00 & - & 4.80 \\
\hline Pancreas (157) & 1 & 0.81 & 1.24 & 0.02 & 6.89 \\
\hline Lung (162) & 4 & 3.52 & 1.14 & 0.31 & 2.91 \\
\hline Prostate (177) & 7 & 5.89 & 1.19 & 0.48 & 2.45 \\
\hline Testis (178) & 0 & 0.30 & 0.00 & - & 12.11 \\
\hline Kidney (180) & 0 & 1.34 & 0.00 & - & 2.75 \\
\hline Bladder (181) & 5 & 1.92 & 2.60 & 0.84 & 6.08 \\
\hline Skin melanoma (190) & 0 & 0.35 & 0.00 & - & 10.63 \\
\hline Other skin (191) & 0 & 0.70 & 0.00 & - & 5.26 \\
\hline Brain (193) & 1 & 0.82 & 1.22 & 0.02 & 6.77 \\
\hline Thyroid (194) & 0 & 0.55 & 0.00 & - & 6.73 \\
\hline Non-Hodgkin's lymphoma $(200,202)$ & 0 & 0.66 & 0.00 & - & 5.52 \\
\hline Multiple myeloma (203) & 1 & 0.35 & 2.90 & 0.04 & 16.13 \\
\hline Leukaemia (204) & 0 & 0.61 & 0.00 & - & 6.02 \\
\hline
\end{tabular}

Table 3 Observed (Obs) and expected (Exp) number of cancers, and SIR (95\% CI) among 567 male printers (15270.0 person-years), followed up during 1955-98

\begin{tabular}{|c|c|c|c|c|c|}
\hline \multirow[b]{2}{*}{ Cancer sites (ICD-7) } & \multirow[b]{2}{*}{ Obs } & \multirow[b]{2}{*}{$\operatorname{Exp}$} & \multirow[b]{2}{*}{ SIR } & \multicolumn{2}{|l|}{$95 \% C I$} \\
\hline & & & & Lower & Higher \\
\hline All cancers $(140-205)$ & 54 & 54.18 & 1.00 & 0.75 & 1.30 \\
\hline Stomach (151) & 8 & 5.69 & 1.41 & 0.61 & 2.77 \\
\hline Colon (153) & 6 & 3.81 & 1.58 & 0.58 & 3.43 \\
\hline Rectum (154) & 0 & 1.45 & 0.00 & - & 2.53 \\
\hline Liver (155) & 2 & 0.87 & 2.29 & 0.26 & 8.26 \\
\hline Pancreas (157) & 1 & 1.60 & 0.63 & 0.01 & 3.48 \\
\hline Lung (162) & 5 & 6.77 & 0.74 & 0.24 & 1.72 \\
\hline Prostate (177) & 13 & 10.70 & 1.21 & 0.65 & 2.08 \\
\hline Testis (178) & 1 & 0.94 & 1.07 & 0.01 & 5.93 \\
\hline Kidney (180) & 1 & 2.93 & 0.34 & 0.00 & 1.90 \\
\hline Bladder (181) & 1 & 3.69 & 0.27 & 0.00 & 1.51 \\
\hline Skin melanoma (190) & 1 & 0.81 & 1.24 & 0.02 & 6.88 \\
\hline Other skin (191) & 1 & 1.36 & 0.73 & 0.01 & 4.08 \\
\hline Brain (193) & 3 & 1.93 & 1.55 & 0.31 & 4.54 \\
\hline Thyroid (194) & 0 & 1.21 & 0.00 & - & 3.04 \\
\hline Non-Hodgkin's lymphoma $(200,202)$ & 2 & 1.53 & 1.31 & 0.15 & 4.72 \\
\hline Multiple myeloma (203) & 0 & 0.67 & 0.00 & - & 5.46 \\
\hline Leukaemia (204) & 0 & 1.32 & 0.00 & - & 2.78 \\
\hline All other sites $(145,150,161,170,179,197$, & 9 & 690 & 130 & 060 & 248 \\
\hline
\end{tabular}

Table 4 Observed (Obs) and expected (Exp) number of cancers, and SIR (95\% CI) among 524 male photoengravers and typesetters (14819.5 person-years), followed up during 1955-98

\begin{tabular}{|c|c|c|c|c|c|}
\hline \multirow[b]{2}{*}{ Cancer sites (ICD-7) } & \multirow[b]{2}{*}{ Obs } & \multirow[b]{2}{*}{$\operatorname{Exp}$} & \multirow[b]{2}{*}{$S I R$} & \multicolumn{2}{|c|}{$95 \% C I$} \\
\hline & & & & Lower & Higher \\
\hline All cancers $(140-205)$ & 48 & 41.64 & 1.15 & 0.85 & 1.53 \\
\hline Stomach $(151)$ & 2 & 3.71 & 0.54 & 0.06 & 1.95 \\
\hline Colon (153) & 6 & 2.86 & 2.10 & 0.77 & 4.57 \\
\hline Rectum (154) & 1 & 1.09 & 0.92 & 0.01 & 5.10 \\
\hline Liver (155) & 2 & 0.63 & 3.17 & 0.36 & 11.46 \\
\hline Pancreas (157) & 1 & 1.17 & 0.85 & 0.01 & 4.74 \\
\hline Lung (162) & 6 & 5.40 & 1.11 & 0.41 & 2.42 \\
\hline Prostate (177) & 8 & 7.62 & 1.05 & 0.45 & 2.07 \\
\hline Testis (178) & 3 & 0.92 & 3.26 & 0.66 & 9.53 \\
\hline Kidney (180) & 3 & 2.28 & 1.32 & 0.26 & 3.84 \\
\hline Bladder (181) & 3 & 2.95 & 1.02 & 0.20 & 2.97 \\
\hline Skin melanoma (190) & 0 & 0.79 & 0.00 & - & 4.66 \\
\hline Other skin (191) & 1 & 0.98 & 1.02 & 0.01 & 5.69 \\
\hline Brain (193) & 0 & 1.75 & 0.00 & - & 2.09 \\
\hline Thyroid (194) & 1 & 1.03 & 0.97 & 0.01 & 5.39 \\
\hline Non-Hodgkin's lymphoma $(200,202)$ & 6 & 1.35 & 4.46 & 1.63 & 9.70 \\
\hline Multiple myeloma (203) & 0 & 0.53 & 0.00 & - & 6.96 \\
\hline Leukaemia (204) & 1 & 1.06 & 0.95 & 0.01 & 5.27 \\
\hline All other sites $(160,161,170,199)$ & 4 & 5.52 & 0.72 & 0.19 & 1.86 \\
\hline
\end{tabular}

two cancers were observed; one prostate cancer and one soft tissue sarcoma.

The photoengravers and typesetters combined had a non-significantly increased overall cancer incidence (table 4). Significantly increased risk was found for non-Hodgkin's lymphoma (SIR 4.46, 95\% CI 1.63 to 9.70 ). Non-significant excess risks were found for cancer of the colon, liver, and testis.

Typesetters had significantly increased risk of all cancer sites (SIR 1.34, 95\% CI 0.97 to 1.81) and non-Hodgkin's lymphoma (SIR $4.99,95 \%$ CI 1.61 to 11.63 , table 5 ). A non-significantly increased risk was found for primary liver cancer (SIR 4.21, 95\% CI 0.47 to 15.20). When a 20 year lag time was allowed between finishing vocational training and the start of counting person-years, the typesetters had a significantly increased risk of nonHodgkin's lymphoma (observed $5 v$ expected 0.89 , SIR $5.59,95 \%$ CI 1.80 to 13.05 ). With 30 years lag time the typesetters had even higher risk for non-Hodgkin's lymphoma (observed 4 $v$ expected 0.74 , SIR 5.43, 95\% CI 1.46 to 13.90). Photoengravers were a smaller and younger group than typesetters and among them no increased risk of cancer was found.

Table 6 shows the observed and expected number of cases, the SIRs, and 95\% CIs for selected cancer sites among all women. There was a deficit for all cancers based on 29 observed versus 32.94 expected. Results for the 199 women who had worked in bookbindingthe largest subgroup of women, which also had the longest career in the printing industry - are shown in table 7 . The cancer sites with highest SIRs were the pancreas (SIR 3.42) and skin melanoma (SIR 3.68), based each on two cases yielding wide $95 \%$ CIs which included unity. Among the women classified as printers $(n=23)$, photoengravers and typesetters $(n=141)$, and others $(n=63)$ no increased risk for any cancer site was found.

Table 8 shows the smoking habits among members of the trade union and a random sample of Icelandic men and women. There are fewer smokers among the trade union members of men and women alike.

\section{Discussion}

The most significant finding in this study is the excess of non-Hodgkin's lymphoma in the total cohort and particularly among the typesetters. An increased SMR for malignant lymphoma was found among typesetters in a study of United States veterans by occupation ${ }^{12}$ and increased risk was found among printers and typesetters in a case-control study. ${ }^{13}$ NonHodgkin's lymphomas were found to be significantly in excess in a proportionate mortality study of commercial pressmen, ${ }^{14}$ and cancer registry studies, performed in a similar way, have found an increased risk for nonHodgkin's lymphoma among male printing press operators and white women from the printing industry. ${ }^{15} 16$ All these cited studies, which have found increased risks for nonHodgkin's lymphoma among people from the printing industry are from the United States, and such an association has not often been 
Table 5 Observed (Obs) and expected (Exp) number of cancers, and SIR (95\% CI) among 315 male typesetters (10257.5 person-years), followed up during 1955-98

\begin{tabular}{|c|c|c|c|c|c|}
\hline \multirow[b]{2}{*}{ Cancer sites (ICD-7) } & \multirow[b]{2}{*}{ Obs } & \multirow[b]{2}{*}{$\operatorname{Exp}$} & \multirow[b]{2}{*}{ SIR } & \multicolumn{2}{|c|}{$95 \% C I$} \\
\hline & & & & Lower & Higher \\
\hline All cancers (140-205) & 42 & 31.28 & 1.34 & 0.97 & 1.81 \\
\hline Stomach (151) & 2 & 2.86 & 0.70 & 0.08 & 2.53 \\
\hline Colon (153) & 5 & 2.16 & 2.32 & 0.75 & 5.40 \\
\hline Rectum (154) & 1 & 0.84 & 1.19 & 0.02 & 6.64 \\
\hline Liver (155) & 2 & 0.48 & 4.21 & 0.47 & 15.20 \\
\hline Pancreas (157) & 1 & 0.88 & 1.13 & 0.01 & 6.30 \\
\hline Lung (162) & 5 & 4.08 & 1.23 & 0.40 & 2.86 \\
\hline Prostate (177) & 7 & 5.75 & 1.22 & 0.49 & 2.51 \\
\hline Testis (178) & 1 & 0.55 & 1.82 & 0.02 & 10.15 \\
\hline Kidney (180) & 3 & 1.75 & 1.71 & 0.34 & 5.00 \\
\hline Bladder (181) & 3 & 2.24 & 1.34 & 0.27 & 3.92 \\
\hline Skin melanoma (190) & 0 & 0.57 & 0.00 & - & 6.48 \\
\hline Other skin (191) & 1 & 0.73 & 1.37 & 0.02 & 7.64 \\
\hline Brain (193) & 0 & 1.29 & 0.00 & - & 2.84 \\
\hline Thyroid (194) & 1 & 0.78 & 1.28 & 0.02 & 7.10 \\
\hline Non-Hodgkin's lymphoma $(200,202)$ & 5 & 1.00 & 4.99 & 1.61 & 11.63 \\
\hline Multiple myeloma (203) & 0 & 0.40 & 0.00 & - & 9.12 \\
\hline Leukaemia (204) & 1 & 0.79 & 1.27 & 0.02 & 7.05 \\
\hline All other sites $(160,161,170,199)$ & 4 & 4.13 & 0.97 & 0.26 & 2.48 \\
\hline
\end{tabular}

Table 6 Observed (Obs) and expected (Exp) number of cancers, and SIR (95\% CI) among 426 female bookbinders, printers, photoengravers, and typesetters (8631.0 person-years), followed up during 1955-98

\begin{tabular}{|c|c|c|c|c|c|}
\hline \multirow[b]{2}{*}{ Cancer sites (ICD-7) } & \multirow[b]{2}{*}{ Obs } & \multirow[b]{2}{*}{$\operatorname{Exp}$} & \multirow[b]{2}{*}{$S I R$} & \multicolumn{2}{|c|}{$95 \% C I$} \\
\hline & & & & Lower & Higher \\
\hline All cancers $(140-205)$ & 29 & 32.94 & 0.88 & 0.59 & 1.26 \\
\hline Stomach (151) & 1 & 1.22 & 0.82 & 0.01 & 4.56 \\
\hline Colon (153) & 2 & 1.90 & 1.05 & 0.12 & 3.79 \\
\hline Rectum (154) & 1 & 0.72 & 1.40 & 0.02 & 7.77 \\
\hline Pancreas (157) & 2 & 0.79 & 2.54 & 0.29 & 9.16 \\
\hline Lung (162) & 4 & 3.19 & 1.25 & 0.34 & 3.21 \\
\hline Breast (170) & 4 & 8.94 & 0.45 & 0.12 & 1.15 \\
\hline Cervix uteri (171) & 1 & 1.79 & 0.56 & 0.01 & 3.11 \\
\hline Corpus uteri (172) & 2 & 1.67 & 1.20 & 0.13 & 4.33 \\
\hline Ovary (175) & 1 & 2.13 & 0.47 & 0.01 & 2.61 \\
\hline Kidney (180) & 1 & 1.02 & 0.98 & 0.01 & 5.45 \\
\hline Bladder (181) & 2 & 0.71 & 2.83 & 0.32 & 10.23 \\
\hline Skin melanoma (190) & 2 & 0.89 & 2.25 & 0.25 & 8.11 \\
\hline Other skin (191) & 0 & 0.54 & 0.00 & - & 6.83 \\
\hline Non-Hodgkin's lymphoma $(200,202)$ & 0 & 0.62 & 0.00 & - & 5.92 \\
\hline All other sites $(141,152,193,194,196,197)$ & 6 & 6.81 & 0.88 & 0.32 & 1.92 \\
\hline
\end{tabular}

Table 7 Observed (Obs) and expected (Exp) number of cancers, and SIR (95\% CI) among 199 female bookbinders (5023.0 person-years), followed up during 1955-98

\begin{tabular}{|c|c|c|c|c|c|}
\hline \multirow[b]{2}{*}{ Cancer sites (ICD-7) } & \multirow[b]{2}{*}{ Obs } & \multirow[b]{2}{*}{$\operatorname{Exp}$} & \multirow[b]{2}{*}{$S I R$} & \multicolumn{2}{|c|}{$95 \% C I$} \\
\hline & & & & Lower & Higher \\
\hline All cancers (140-205) & 23 & 23.79 & 0.97 & 0.61 & 1.45 \\
\hline Stomach $(151)$ & 0 & 0.92 & 0.00 & - & 4.00 \\
\hline Colon (153) & 0 & 1.43 & 0.00 & - & 2.56 \\
\hline Rectum (154) & 1 & 0.53 & 1.89 & 0.02 & 10.52 \\
\hline Pancreas (157) & 2 & 0.58 & 3.42 & 0.38 & 12.36 \\
\hline Lung (162) & 4 & 2.45 & 1.63 & 0.44 & 4.18 \\
\hline Breast (170) & 2 & 6.46 & 0.31 & 0.03 & 1.12 \\
\hline Cervix uteri (171) & 1 & 1.12 & 0.89 & 0.01 & 4.95 \\
\hline Corpus uteri (172) & 2 & 1.29 & 1.55 & 0.17 & 5.60 \\
\hline Ovary (175) & 1 & 1.49 & 0.67 & 0.01 & 3.74 \\
\hline Kidney (180) & 1 & 1.30 & 0.77 & 0.01 & 4.29 \\
\hline Bladder (181) & 1 & 0.52 & 1.91 & 0.02 & 10.62 \\
\hline Skin melanoma (190) & 2 & 0.54 & 3.68 & 0.41 & 13.27 \\
\hline Other skin (191) & 0 & 0.40 & 0.00 & - & 9.15 \\
\hline Non-Hodgkin's lymphoma $(200,202)$ & 0 & 0.42 & 0.00 & - & 8.73 \\
\hline All other sites $(141,152,193,194,196,197)$ & 6 & 4.34 & 1.38 & 0.50 & 3.01 \\
\hline
\end{tabular}

Table 8 Smoking habits of a random sample of Icelandic men $(n=1320)$ and women $(n=1390)$ and of trade union members (men, $n=450$, and women $n=205$ ), age range $15-89$ years

\begin{tabular}{|c|c|c|c|c|}
\hline \multirow[b]{2}{*}{ Smoking categories } & \multicolumn{2}{|c|}{ Population sample } & \multicolumn{2}{|c|}{ Trade union members } \\
\hline & Men $n(\%)$ & Women n (\%) & Men $n(\%)$ & Women $n(\%)$ \\
\hline $\begin{array}{l}\text { Never smoked } \\
\text { Stopped smoking: }\end{array}$ & $569(43.1)$ & $627(45.1)$ & $180(40.0)$ & $91(44.4)$ \\
\hline$>1$ y ago & $301(22.8)$ & $292(21.0)$ & $150(33.3)$ & $61(29.8)$ \\
\hline$<1$ y ago & $65(4.9)$ & $52(3.7)$ & $25(5.6)$ & $6(2.9)$ \\
\hline Smoker, not daily & $62(4.7)$ & $77(5.6)$ & $25(5.6)$ & $9(4.4)$ \\
\hline Smoker, daily & $324(24.5)$ & $341(24.5)$ & $70(15.6)$ & $38(18.5)$ \\
\hline
\end{tabular}

found in European studies. ${ }^{2-4} 6{ }^{17}$ A mortality study from the British printing industry ${ }^{18}$ is an exception showing non-significantly increased risks of non-Hodgkin's lymphoma. NonHodgkin's lymphoma and certain subtypes of non-Hodgkin's lymphoma have been related to cigarette smoking in studies from the United States. ${ }^{19-21}$ The results from the present smoking survey indicated that the men and women in the cohort smoked less than the comparison population. Exposure to organic solvents has been related to non-Hodgkin's lymphoma in a previous study ${ }^{22}$ and such exposure may be considered to contribute to the increased risk of non-Hodgkin's lymphoma found among the typesetters. Printers (typographers, offset printers, lithographers) have been considered to sustain heavier exposure to solvents than the typesetters; however, increased risk of nonHodgkin's lymphoma was not found among the printers in the present study.

Previous studies on printing workers have found excesses of lung cancer, ${ }^{2-3} 1823$ bladder cancer, ${ }^{218}$ and renal pelvis cancer, ${ }^{2}$ these cancers were, however, not found in excess in the present study. In recent studies the authors have stressed the importance of describing the different exposure in the printing industry relative to the risk of cancer, as the risk of the different cancer sites may be confined to certain subgroups. $^{23}$

As both lung cancer and bladder cancer, which are related to smoking habits, have been found in excess among printers in previous studies an attempt was made in the present study to indirectly evaluate the effect of smoking. Assuming the risk of lung cancer to be 1 for non-smokers, 5 for ex-smokers, and 10 for smokers, the predictive value for lung cancer was 0.92 among men and 0.95 for women according to Axelson and Steenland. ${ }^{11}$ This indirect evaluation of the possible confounding due to smoking on the incidence of lung cancer showed that a lower incidence of lung cancer in the cohort could be expected than in the general population. There are two other cohort studies of printing workers that indirectly control for tobacco smoking. ${ }^{23}$ The proportion of smokers in these cohorts was higher than in the comparison populations, although it was concluded, in both cases, that excessive smoking was unlikely to explain entirely the increased risk of lung cancer found. ${ }^{23}$ In these studies of Danish and French printing workers, ${ }^{23} 19 \%-$ $20 \%$ had never smoked whereas more than $40 \%$ in the present study had never smoked. If the excess risk of lung cancer among workers in the printing industry ${ }^{2}$ is caused by the joint action of smoking and work related exposure, it may be difficult to detect the risk of lung cancer in the present cohort because of the low prevalence of smokers. Furthermore, the same thing can possibly explain why increased risk of bladder and renal cancer was not found in the present study.

The excess risk of non-Hodgkin's lymphoma was not hypothesised initially among the employees in the printing industry; the aim was to study, according to different occupations, the risk of cancer in general and in particular 
the risk of lung and bladder cancer. When non-Hodgkin's lymphoma turned out to be confined to the group of photoengravers and typesetters it was considered of interest to divide the group according to occupation as they have different exposures.

In the present study in which the cohort of trade union workers was divided into occupational groups, besides looking for the risk of bladder cancer and lung cancer and also analysing the cohort for the risk of cancer at other sites, concern about the need of adjustment for multiple comparisons may arise. There is no general agreement on how to approach this phenomenon ${ }^{24}{ }^{25}$; some maintain that no correction is needed for multiple comparison ${ }^{25}{ }^{26}$ whereas others advocate the use of 95\% CIs rather than deciding merely from $\mathrm{p}$ values whether significant or non-significant results have been obtained. ${ }^{27}$ Nevertheless this calls for different interpretation of results for different cancer sites. ${ }^{927}$

The healthy worker effect is in general not as prominent in cancer studies as in mortality studies and this phenomenon was not found in the present study. The healthy worker effect is a type of confounding bias as healthier people tend to be employed and are compared with the general population which includes workers and people unable to work due to illnesses and disabilities.

The small size of the cohort and the lack of a more detailed information on exposure is an obvious drawback of the study. The vocational training for tradesmen is 4 years, which is the minimum exposure in printing work. According to the survey the men and women (bookbinders, printers, and photoengravers or typesetters) had practised their profession for several years. The measurement of organic solvents in the printing shops in 1986 were all done in the press rooms and thus describes the exposure of the printers but not that of the bookbinders, and photoengravers or typesetters at that time.

The strength of the study is the use of the comprehensive population registries in Iceland, especially the Icelandic Cancer Registry. Workers in the printing trade did not attend any special or regular medical examinations due to their occupation so bias related to cancer detection is unlikely to have been introduced, keeping in mind the comprehensive healthcare system. The universal use of the personal identification numbers made record linkage possible, which ascertained $100 \%$ follow up and identification of cases of cancer.

In conclusion there was an increased risk of non-Hodgkin's lymphoma found among typesetters. Exposure to organic solvents may play a part in this relation, however, the typesetters were also exposed to lead in the form of dust or fumes in their professional careers. Casereferent studies nested in cohorts of printing workers may be the only way to elucidate the potential risk of cancer or risks associated with the occupations in the printing processes.

1 International Agency for Research on Cancer. IARC monographs on the evaluation of carcinogenic risks to humans. Printing processes and printing inks, carbon black and some nitro compounds. Vol 65. Lyon, France: World Health Organization, 1996.

2 Lynge E, Andreassen Rix B, Villadsen E, et al. Cancer in printing workers in Denmark. Occup Environ Med 1995;52: 738-44.

3 Luce D, Landre M-F, Clavel T, et al. Cancer mortality among magazine printing workers. Occup Environ Med 997;54:264-7.

4 Bulbulyan MA, Ilychova SA, Zahm SH, et al. Cancer mortality among women in the Russian printing industry. Am f Ind Med 1999;36:166-71.

5 Stéttartal Bókagerdamanna. (The Register of the Trade Union of Printers and Bookbinders). Reykjavík, Iceland: ódsaga, 1997.

6 Greene MH, Hoover RN, Eck RL, et al. Cancer mortality among printing plant workers. Environ Res 1979;20:66-73.

7 Gunnarsdóttir H, Jóhannesdóttir S, Rafnsson V. Dánarmein bókagerdarmanna á Íslandi. Leknabladid 1987;73:160-7.

8 Tulinius H, Ragnarsson J. Cancer incidence in Iceland 1955-84. Reykjavík, Iceland: Cancer Society and Director 1955-84. Reykjavik, Icela
General of Health, 1987.

9 Breslow NE, Day NE. Statistical methods in cancer research. Vol II. The design and analysis of cohort studies. Lyon: International Agency for Research on Cancer, 1987

10 Tóbaksvarnarnefnd. Reykingar á Íslandi. Ársskýrsla 1999. Reykjavík, Iceland: Pricewaterhouse Coopers ehf, 1999.

11 Axelson O, Steenland K. Indirect methods of assessing the effects of tobacco use in occupational studies. Am $\mathcal{F}$ Ind Med 1988;13:105-18.

12 Blair A, Walrath J, Rogot E. Mortality patterns among US veterans by occupation. I. Cancer. F Natl Cancer Inst 1985; 75:1039-47.

13 Blair A, Linos A, Stewart PA, et al. Evaluation of risks for non-Hodgkin's lymphoma by occupation and industry exposures from a case-control study. Am 7 Ind Med 1993;23:301-12.

14 Zoloth SR, Michaels DM, Villalbi JR, et al. Patterns of mortality among commercial pressmen. I Natl Cancer Inst 1986;76:1047-51.

15 Brownson RC, Reif JS. A cancer registry-based study of occupational risk for lymphoma, multiple myeloma and leukaemia. Int f Epidemiol 1988;17:27-32.

16 Hall NEL, Rosenman KD. Cancer by industry: analysis of a population-based cancer registry with an emphasis on blue-collar workers. Am f Ind Med 1991;19:145-59.

17 Linet MS, Malker HSR, McLaughlin JK, et al. NonHodgkin's lymphoma and occupation in Sweden: a registry based analysis. Br F Ind Med 1993;50:79-84.

18 Leon DA. Morality in the British printing industry: a historical cohort study of trade union members in Manchester. Occup Environ Med 1994;51:79-86.

19 Linet SM, McLaughin JK, Hsing AW, et al. Is cigarette smoking a risk factor for non-Hodgkin's lymphoma or multiple myeloma? Results from the Lutheran Brotherhood cohort study. Leukemia Res 1992;16:621-4.

20 Brown LM, Everett GD, Gibson R, et al. Smoking and risk of non-Hodgkin's lymphoma and multiple myeloma. Cancer Causes Control 1992;3:49-55.

21 Freedman DS, Tolbert PE, Coates R, et al. Relation of cigarette smoking to non-Hodgkin's lymphoma among middlerette smoking to non-Hodgkin's lymphoma an

22 Olsson H, Brandt L. Risk of non-Hodgkin's lymphoma among men occupationally exposed to organic solvents. Scand F Work Environ Health 1988;14:246-51.

23 Malker HSR, Gemne G. A register-epidemiology study on cancer among Swedish printing industry workers. Arch Environ Health 1987;42:73-82.

24 Armitage P, Berry G. Statistical methods in medical research. Oxford: Blackwell Scientific, 1991.

25 Rothman KJ. Modern epidemiolgy. Boston: Little, Brown, 1986.

26 Rothman KJ. No adjustments are needed for multiple comparison. Epidemiology 1990;1:43-6.

27 Hernberg S. Introduction to occupational epidemiology. Chelsea: Lewis, 1992. 